\title{
TOOTH SIZE AND APPROXIMAL DECAY IN HUMAN TEETH
}

\author{
W. S. HUNTER \\ Department of Orthodontics, School of Dentistry, University of Michigan, \\ Ann Arbor, Michigan, U.S.A.
}

As PART of a study of spacing-crowding at the Burlington Orthodontic Research Centre, cognisance was taken of the presence of mesial and distal restorations in primary molars in the sample. Since at age nine, more than half the sample of primary molars which could be measured had such restorations, the validity of the spacingcrowding data could be questioned. Specifically, it was of interest to know whether the approximal restorations made the mesio-distal dimensions of the teeth so restored larger or smaller and whether the caries attack as represented by approximal restorations had a predilection for larger or smaller teeth.

In answer to the first question, it was found possible to locate at least thirteen subjects who had approximal restorations in primary maxillary molars (substantiated radiographically) on one side only. Since left-right differences in unrestored primary molars were found in the larger study (HUNTER, 1960-1) to be of the average order of $0.03 \mathrm{~mm}$, symmetry was assumed to have existed prior to restoration. The restored maxillary primary molars proved to be, on the average, $0.18 \mathrm{~mm}$ smaller than their non-carious unrestored antimeres. A similar mandibular comparison for eight subjects showed the restored teeth to be on the average, $0.07 \mathrm{~mm}$ smaller than their unrestored antimeres. Therefore, it was concluded that the process of restoration of approximal decay did not, on the average, significantly enlarge the size of the primary molars but rather tended, to an insignificant extent, to diminish their size by the observed amounts. It is possible that the dentists of Burlington who completed these restorations had a slight tendency to underpack their restorations-possibly related to the difficulty of wedging primary molars.

Some significance may then be attached to the finding that at age six, 491 restored primary molars were on the average $0.28 \mathrm{~mm}$ larger than 1365 unrestored molars. At age nine, 814 restored primary molars were found, on the average, to be $0.16 \mathrm{~mm}$ larger than 723 non-carious unrestored teeth. These differences exceed by a factor of 10 the average measurement errors found for the primary molar measurements. (HUNTER, 1960-1). Sixteen comparisons were made at the two ages, each involving at least eighteen subjects. Of the thirty-two comparisons made, thirty-one showed the restored molars to be larger and twenty of these differences were statistically significant at the 5 per cent level. Four representative comparisons are shown in Table 1 for mandibular left second primary molars.

Similar comparisons were made for right mandibular second primary molars, 
TABLE 1. SUMMARY OF FOUR REPRESENTATIVE " $t$ " TESTS OF THE DIFFERENCES IN MESIODISTAL TOOTH DIAMETER BETWEEN UNDECAYED AND RESTORED PRIMARY MANDIBULAR SECOND MOLARS $\left(\mathrm{dm}_{2}\right)$

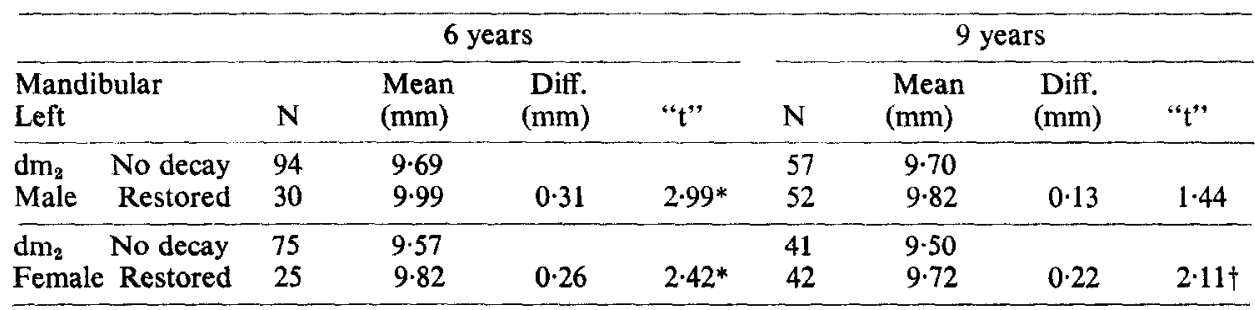

*Difference significant at $1 \%$ level

$\nmid$ Difference significant at $5 \%$ level

for all first primary molars and for maxillary second primary molars. The differences ranged from a low of $0.05 \mathrm{~mm}$ to a high of $0.44 \mathrm{~mm}$.

It is probable then that the restored teeth, on the average, were themselves larger than the unrestored teeth, since the restorations could not be shown to have enlarged the teeth so restored but rather to have diminished their size to a very slight extent.

Since a low positive correlation of $\mathbf{0 . 4}$ has been shown by MOORREES and REED, (1964) to exist between permanent incisors and primary molars and canine, a comparison of anterior tooth size in undecayed and in restored mouths seemed worthwhile. It was found that the sum of the mesiodistal widths of the four permanent maxillary incisors for sixty subjects having aeproximal restorations in the primary molars was $0.63 \mathrm{~mm}$ greater, on the average, than for nineteen subjects having no decay. The mandibular incisors were $0.51 \mathrm{~mm}$ larger under similar conditions. It was, therefore, concluded that decay, as represented by approximal restorations, occurs more frequently in dentitions having large tecth than in dentitions having small teeth.

This conclusion is in agreement with the work of PAYNTER and GraINGER (1961) in which a distinct tendency was found for the buccolingual diameter of first permanent molars in humans to be greater in the presence of decay than when no decay was present.

It is possible then, that a long held suspicion that crowding is associated with a high incidence of decay has some merit through the common factor of large teeth.

\section{REFERENCES}

HUNTER, W. S. 1960-1. Tooth size, spacing-crowding, arch relationships and arch dimensions in an orthodontically supervised group, pp. 31-83 in: Report No. 6, Burlington Orthodontic Research Centre, Ontario, Canada.

Moorrees, C. F. A. and ReED, R. B. 1964. Correlations among crown diameters of human teeth. Archs oral Biol. 9, 685-697.

Paynter, K. J. and Grainger, R. M. 1961. Influence of nutrition and genetics on morphology and caries susceptibility. J. Am. med. .4ss. 177, 306-309. 